\title{
Analysis on the Construction Demand and Objective of Xiangyin Port in Hu'nan
}

\author{
Shijun Yuan \\ Hunan Modern Logistics College \\ Changsha, China 410131
}

\author{
Ruiwei Liang \\ Hunan Modern Logistics College \\ Changsha, China 410131
}

\author{
Jianhua Chen* \\ Hunan Modern Logistics College \\ Changsha, China 410131 \\ *Corresponding Author
}

\begin{abstract}
This paper puts forward the basic principle and development objective of construction of Xiangyin port in Hu'nan province over a deep investigation on the current water transport status and development trend of various industries in Hu'nan.
\end{abstract}

Keywords-Xiangyin port; construction; objective

\section{INTRODUCTION}

Xiangyin is the only way to go to sea from ChangshaZhuzhou-Xiangtan region along the Xiangjiang River, passing over Dongting Lake and Yangtze River. It is not only the "Big Wharf" of "Changsha-Zhuzhou-Xiangtan" urban agglomeration to go to Dongting Lake along Yangtze River, but also the "Bridgehead" of Yueyang and Wuyang urban circle connected to "Changsha-Zhuzhou-Xiangtan" urban agglomeration. In recent years, Xiangyin pays highly attention to the development of water transport. The investment scale is increased prominently. Water transport facilities are improved. Water transport capacity is unceasingly improved and the role of water transport in economic and social development is gradually enhanced.

\section{CURRENT STATUS OF WATER TRANSPORT LOGISTICS IN HU'NAN}

\section{A. The Water Transport Capacity Is Improved}

Continuously and the Role of Water Transport in

Economic and Social Development Is Increased Gradually

In 2016, Hunan's water-transport cargo volume was about 230 million tons, waterway cargo turnover was 62 billion ton kilometer, and the cargo throughput in major port was 300 million tons.

\section{B. There Are Rich Shipping Resources but the Level of Channels of the Whole Province Is Low and the Overall Utilization Rate Is Low}

By the end of 2015, the Province's inland waterway navigation mileage was $11,968 \mathrm{~km}$ and the navigation mileage in channel of level was $4,216 \mathrm{~km}$, accounting for $35.2 \%$ of the total mileage. Wherein, $700 \mathrm{~km}$ lies in channel superior to 1000 tonnage. The inland ports have 1,855 berths for production use and ports of the whole province have 106 berths not inferior to 1,000 tonnage. Wherein, there are 49 specialized berths, 16 general-purpose bulk berths, 29 general-purpose groceries, 6 break-bulk berths and 6 other berths.

C. There Are Complete Types of Goods Available to Be Transported but the Low Value-added Mineral Building Materials Such as Sandstone Accounts for the Most Percentage

Water transport involves in all the 17 types of goods. Wherein, coal and its products, mechanical equipment and appliances, cement, wood, non-metallic ore, light industry and medicine products enjoy an average annual growth rate of more than $20 \%$. However from the perspective of composition, there are mainly mineral construction materials, and $90 \%$ of the mineral construction materials are sandstone.

\section{DEVELOPMENT TREND OF VARIOUS INDUSTRIES IN HU'NAN}

From the perspective of development trend, the demand for water transport in economic and social development is continuously increased. Considering the water transport and its closely related industries in Hu'nan include metallurgy, petrochemical, thermal power, building materials, equipment manufacturing, and special light industry and so on, it is expected that to 2020 Hunan's water-transport cargo volume will reach about 3500 million tons over a prediction on the basis of quantitative and qualitative analysis, a comprehensive consideration on relevant factors and their 
change affecting the development of volume of water transportation and a linear model and curve model combined prediction.

\section{A. Development Trend of Metallurgical Industry}

Metallurgical industry in Hu'nan includes Fe-Mn ore, steel, iron alloy, steel structure, refractory and other related industries. According to the "13th Five-Year Plan" of metallurgical industry in Hu'nan Province, by 2020, the province(excluding Valin in other province)'s crude steel output will be controlled at 20 million tons, iron alloy output will be controlled at 2 million tons and the output of electrolytic manganese metal will be controlled at 300,000 tons. The Province's metallurgical industry will realize main business revenue of 250 billion Yuan.

\section{B. Development Trend of Petrochemical Industry}

According to the "13th Five-Year Plan" of petrochemical industry in Hu'nan Province, by 2020, the main business income of the whole industry will reach 360 billion Yuan at an annual average increase rate of $8 \%$; the industrial added value will be 90 billion Yuan at an annual average increase rate of $8 \%$. It is going to vigorously develop petroleum refining integrated industry and the middle and downstream industries in the north of Hu'nan Province, accelerate the development of new chemical materials industry in Changsha-Zhuzhou-Xiangtan region, and focus on supporting the transformation and upgrading of salt (fluorine) chemical and coal chemical industries in southern Hu'nan and strive to promote the development of fine chemical industry in the grand north of Hu'nan.

\section{Development Trend of Building Materials Industry}

According to the "13th Five-Year Plan" of the metallurgical industry in Hu'nan Province, by 2020, the Province's cement output will be around 110 million tons and the building ceramics output will reach 250 million $\mathrm{m} 2$. By 2020, the concentrated development of building materials industry clusters has achieved remarkable results. It is going to form into 3 5 concentrated production areas for producing characteristic building materials in the core area and periphery of Changsha-Zhuzhou-Xiangtan region, focus on the development of building parts and elements, new wall materials, special ceramics, technical glass, chemical building materials, silicon materials and graphite deep processing and other products to provide supporting materials for building Industrialization and greening development.

\section{Development Trend of Equipment Manufacturing Industry}

From the perspective of industrial layout, the province initially forms into the mechanical engineering, electronic information, rail transit, electrical \& electronics and automobile oriented five major industrial clusters by executing industrial clusters development strategy and having Sany Heavy Industry, Zoomlion, Lens Technology and CRRC developed to drive the development of the industrial chain. Wherein, it forms into the engineering machinery industry cluster and the electronic information industry cluster centered on Changsha, the rail transit industry cluster centered on Zhuzhou and the automobile industry cluster centered on Changsha and Xiangtan. According to the development plan of equipment manufacturing industry in Hu'nan Province, by 2020, the sales revenue will be more than 1500 billion Yuan and the export value will be more than 150 billion Yuan. The export income will account for about $10 \%$ of the main business income.

\section{E. Development Trend of Light Industry}

Based on the resources and comparative advantages, the province vigorously develops light industry and forms into a relatively complete light industrial system including papermaking, furniture, leather, arts and crafts, plastic products, daily-use ceramics, fireworks and crackers, household appliances, household chemicals, lighting equipment and so on. Wherein, fireworks and daily-use ceramics are the traditional characteristic sub-industries of the province. Liuyang has become the largest production base of fireworks and crackers in the global. Fireworks production accounts for more than $50 \%$ of that in the whole country. The product quality level ranks top in the world; Liling daily-use ceramics export amount has been stably ranking second in daily-use ceramics production areas of China for many years successively.

According to the "13th Five-Year Plan" of light industry in Hu'nan Province, by 2020, the Province's above-scale light industrial enterprises will achieve an industrial added value of 230 billion Yuan at an annual average growth rate of about $8.5 \%$, and realize the main business income of 760 billion Yuan at an annual average growth rate of $8 \%$. Changsha will focus on the construction of Liuyang fireworks industry cluster, Changsha household appliance industry cluster, Changsha furniture industry cluster and so on to realize an added value of 51.56 billion Yuan at a predicted annual average growth rate of $8.6 \%$ and a main business income of 173.26 billion Yuan at an annual average growth rate of $10 \%$.

\section{DEVElOPMENT TREND OF WATER TRANSPORT LOGISTICS IN HU'NAN}

\section{A. The Rapid Development of Various Industries Such as Metallurgy, Building Materials and Equipment Manufacturing Provides Opportunities for the Development of Xiangyin Port}

According to the "13th Five-Year Plan" of metallurgical, petrochemical, building materials, equipment manufacturing, light industry and other industries in Hu'nan Province, the output of major industrial products in the province will increase sharply, especially in the Changsha-ZhuzhouXiangtan region. How to select an effective mode of transportation will be the key point.

First, freight rate by water transport is relatively low. It is estimated that the average freight rate/ $\mathrm{t} \mathrm{km}$ of enterprise is 0.0195 Yuan, only accounting for $30.8 \%$ of that by highway 
$\left(0.0634\right.$ Yuan / $\mathrm{t}^{\mathrm{km}}$ ) and $12.6 \%$ of that by railway (base price: 0.1551 Yuan / $\mathrm{t}^{`} \mathrm{~km}$ ). Second, the input-output ratio by water transport is relatively high. According to historical statistics, during 2012 2014, the Province's investment on water transport accounted for $4.4 \%$ of all transportation investment and the freight volume accounted for $11.7 \%$; road transport investment accounted for $71.5 \%$ and the freight volume accounted for $85.7 \%$. It can be seen that water transport carries $11.7 \%$ of the total freight volume with $4.4 \%$ investment, and the highway has completed $85.7 \%$ of the total freight volume with $71.5 \%$ investment. Hence, the input-output ratio by water transport is significantly higher than that by highway.

\section{B. The Unique Water Transport Condition of Xiangyin Port Provides Guarantee for the Implementation of Water Transport Logistics}

At present, the Province's high-grade channels not inferior to Grade 3 and available to carry cargo ship not inferior to 1000 tonnage are very few and only account for $5.8 \%$ and the channel mileage available to carry cargo ship superior to 500 tonnage only accounts for $9 \%$. Xiangyin has its unique location and transportation advantages. The county town is only $38 \mathrm{~km}$ away from downtown of Changsha. Caoxi port and Yugongmiao port are available to carry cargo ship of 3,000-tonnage all the year round. Therefore, Xiangyin port provides a guarantee for the demand of container logistics and bulk cargo logistics.

\section{The Industrial Layout Close to Rivers and Ports and Along Rivers and Around Lakes Earns the First Opportunity for the Development of Xiangyin Port}

The layouts of many industries in the province are close to rivers and ports and along rivers and around lakes. Among the 137 provincial and above level of industrial parks in the province, 41 industrial parks can use ports and Grade-1 and superior channels within their short-distance transportation scope (in urban area). In particular, Xiangjiang economic belt has been developed into the most important industrial corridor in the province. $52.6 \%$ of economic development zones and industrial parks of the province and $81 \%$ of large and medium-sized industrial enterprises are located along Xiangjiang River and around Dongting Lake. Xiangjiang River runs through the whole territory of Xiangyin from the south to north. The length of the Xiangjiang River and Zijiang River run through Xiangyin for more than $260 \mathrm{~km}$ in length and run through Neijiang City for more than $70 \mathrm{~km}$ in length. Xiangyin is the only way to go to sea from Changsha-Zhuzhou-Xiangtan region along the Xiangjiang River, passing over Dongting Lake and Yangtze River. The Province's industrial layout close to rivers and ports and along rivers and around lakes earns the first opportunity for logistics by water transport and even for the development of Xiangyin port.

\section{The Demand for Water Transport logistics Tends to Be Green, Intelligent and Integrated}

Under the pressure of resource environment, green water transport logistics becomes imperative in order to improve operational efficiency and transportation capacity. The socalled "Green Port" is a port under sustainable development that not only saves resources, meets environmental and ecological requirements, but also obtains good economic benefits. The core objective of the port is to achieve harmonious development of ports, society and the environment. At the same time, the Internet, cross-border ecommerce and modern logistics have become the means to transform and upgrade ports and improve competitiveness. Under the continuous innovation and application of a new generation of information technologies such as cloud computing, big data and Internet of Things, Xiangyin port cluster is expected to create smart ports depending on modern information technology. Meanwhile, it is expected to lay emphasis on the division of labor and cooperation, complementing each other's advantages, avoiding cargo supplies overlapping, repetitive construction and homogenized competition in port hinterland and strive to create an integrated port cluster with clear orientation, reasonable layout, clear division of labor, mismatched complementary development and well-organized competition.

\section{CONSTRUCTION PLANNING AND DEVELOPMENT PRINCIPLES AND OBJECTIVES OF XIANGYIN PORT}

\section{A. Basic Principle}

1) Adhere to the combination of planning guide and optimum adjustment: Optimize the spatial layout of logistics hub, logistics nodes and tourism nodes of Xiangyin and research and formulate relevant supporting policies oriented by market demand and based on special plans of Xiangyin County as well as the latest development status of Yueyang City, Xiangyin County, Changsha City and Xiangjiang New Zone and so on and on the basis of a full investigation and research.

2) Adhere to the matching of facilities construction and industrial development: Blend into the industrial development in Xiangyin, Changsha and Xiangjiang New Zone and realize an organic combination of complete hardware facilities and good development environment by promoting advanced management concepts, strengthening port logistics information construction, establishing sound policies and regulations, introducing and nurturing professional port management talents and technical personnel and other construction of intangible infrastructures in addition to speed up the development of port construction, collection and distribution system construction, logistics park and other logistics infrastructure and tourism industrial infrastructure construction in Xiangyin port and build up a water transport and tourism system for Xiangyin port.

3) Adhere to the matching of government's guidance and market dominance: Enhance the dominant position of enterprise in the market, give play to the basic role of market allocation of resources, strengthen government's overall planning and industrial policy guidance, accelerate 
the pace of port infrastructure construction and create a good development environment for the construction of Xiangyin Port.

4) Adhere to the integration of local cultivation and focusing on introduction: Vigorously support local water transport enterprises to become bigger and stronger, encourage association between strong enterprises, intensify efforts to attract foreign investment, introduce domestic and foreign well-known port operators, water transport logistics group companies, tourism industry development group companies to invest and develop in Xiangyin and improve the county's modern logistics industry development.

\section{B. Planning Objectives of Each Port Area of Xiangyin Port}

Fully explore and take fully use of the advantages of Xiangyin port in water transport logistics and biological tourism to make the three port areas of Xiangyin port bigger and stronger.

Planning development objective of Caoxi port area: up to 2018, complete the construction of phase-I project and associated facilities of Caoxi port to get Caoxi port created into a cargo port serving regional economy, oriented by container transportation and associated by bulk cargo transportation. Wherein, the annual throughput of container will reach 50000 standard containers and that of bulk cargo including break-bulk cargo will reach 5 million tons.

Planning development objective of Yugong port area: up to 2019, get Yugong port created into the largest inland river cargo port in Xiangjiang River and Zijiang River water system, oriented by automobile ro-ro terminals and supported by container terminals. Wherein, the annual throughput of container will reach 120000 standard containers and that of commercial vehicles and bulk cargo including break-bulk cargo will reach 45 million tons.

Planning development objective of Zhangshu port area: up to 2021, get Zhangshu port created into an important biological tourism port in Hu'nan water system and around Dongting Lake, with annual throughput of tourists reaching 1 million persons time.

\section{CONCLUSION}

To successfully promote the construction of "Changsha North Port", it is needed to further strengthen organizational leadership, planning guidance and department and district coordination and cooperation, policy supporting, monitoring and evaluation and construction of talent team.

\section{REFERENCES}

[1] Wu Wei. Study on the method of plan construction of port logistics park and application [D]. Nanjing Tech University 2005.

[2] Nie Qi. Discussion on the position and roles of port in modern logistics [D]. Shanghai Maritime University 2000.

[3] He Jie. Analysis on actual condition and corresponding strategy o Chinese port logistics development under the background of "Internet+" [J]. Economic \& Trade. 2017(01).
[4] Tang Feng. Analysis on the route of Chinese port logistics development in new time [J]. China Circulation Economy. 2017(09). 